\title{
Swelling and Degradation of Calcium-Pectic Gel Particles Made of Pectins of Silene vulgaris and Lemna minor Callus Cultures at Different Concentrations of Pectinase in an Artificial Colon Environment
}

\author{
Anatoly A. Shubakov, $\mathrm{PhD}^{1}$; Elena A. Mikhailova ${ }^{1,2^{*}}$; \\ Valentina I. Prosheva, $\mathrm{PhD}^{1}$; Vladimir A. Belyy, $\mathrm{PhD}^{3}$ \\ ${ }^{I}$ Institute of Physiology, Komi Science Centre, Ural Branch of the RAS \\ ${ }^{2}$ Komi Republic Research Institute of Agriculture, Komi Science Centre, Ural Branch of the RAS \\ ${ }^{3}$ Institute of Chemistry, Komi Science Centre, Ural Branch of the RAS \\ Syktyvkar, Komi Republic, the Russian Federation
}

\begin{abstract}
Spherical calcium-pectic gel particles (CaPGPs) were obtained from pectins of callus cultures of campion Silene vulgaris (silenan) and duckweed Lemna minor (lemnan), as well as from commercial apple and citrus pectins by the method of ionotropic gelation. We studied the morphological characteristics of the obtained gel particles and found that the largest gel particles were formed from citrus pectin, and the densest gel particles were formed from lemnan pectin. The swelling and degradation of CaPGPs were comparatively evaluated by incubation in a simulated gastrointestinal environment. The swelling and degradation of CaPGPs formed from pectins of the silenan and lemnan callus cultures were studied at different concentrations of pectinase $(0.4,0.8$ and $1.7 \mathrm{mg} / \mathrm{ml}$ ) in the simulated fluid of the colon. It has been established that the CaPGPs obtained from lemnan are more resistant to degradation in the simulated colon fluid than CaPGP obtained from silenan. It was shown that the concentration of pectinase in the simulated fluid of the colon and the type of pectin affect the degradability of CaPGPs formed on the basis of pectins of callus cultures.(International Journal of Biomedicine. 2018;8(1):60-64.)
\end{abstract}

Key Words: pectins $\bullet$ silenan $\bullet$ lemnan $\bullet$ callus culture $\bullet$ gel particles $\bullet$ gastrointestinal tract $\bullet$ pectinase

\section{Abbreviations}

GIT, gastrointestinal tract; CaPGPs, calcium-pectic gel particles; DDS, drug delivery systems; CP, citrus pectin; LP, lemnan pectin; SP, silenan pectin; LMEPs, low methyl-esterified pectins.

\section{Introduction}

Enzymes secreted by the body, as well as the enzymes of symbiont microflora, participate in the process of digestion. ${ }^{(1)}$ The major components of dietary fibers are cellulose, noncellulose polysaccharides, such as hemicelluloses and pectic substances, and lignin, the non-carbohydrate component. ${ }^{(2)}$

*Corresponding author: Elena A. Mikhailova. Department of Molecular Immunology and Biotechnology, Institute of Physiology, Komi Science Centre, Ural Branch of the RAS. Syktyvkar, the Russian Federation.E-mail: elena_elkina@mail.ru
The complex nature of the pectic macromolecule leads to the existence of a variety of structures of pectins with specific properties. Their carbohydrate chains have an irregular block structure and contain various macromolecular fragments that determine the differences in physico-chemical properties and physiological activity of pectin. Pectins are widely used in the pharmaceutical and food industries due to their nontoxicity and biodegradability, and to their high physiological activity (immunomodulating, antiulcer, antitoxic, antitumor) and gelforming ability. . $^{(3,4)}$

Pectins with the main carbohydrate chain formed by 1,4-linked $\alpha$-D-galactopyranosyluronic acid residues are 
divided into two types: high methyl-esterified (the degree of esterification greater than $50 \%$ ) and low methyl-esterified (the degree of esterification less than $50 \%) \cdot{ }^{(5)}$ Low methyl-esterified pectins (LMEPs) form gels in the presence of calcium ions due to the cross-linking of pectin molecules by calcium ions. The study of pectin gels is of particular interest in connection with the problem of creating new functional materials. ${ }^{(6,7)}$

In human nutrition, pectin is one of the most important sources of dietary fiber. Like other types of dietary fiber, pectin is practically invulnerable to depolymerization by endogenous enzymes of gastrointestinal tract (GIT) when passing through the stomach and small intestine. The physicochemical conditions of the stomach and small intestine can lead just to partial degradation of pectin. In the colon of healthy people and animals, pectin undergoes more or less complete fermentation by pectinolytic enzymes produced by symbiotic microflora. ${ }^{(8)}$ In this case, LMEPs are more preferable substrates for the pectindepolymerizing enzymes of human and animal microflora. ${ }^{(9)}$

Currently, the use of pectins in the form of spherical particles for controlled drug delivery systems (DDS) in the body is being actively studied. CaPGPs delay the release of drugs in the upper GIT and release the drugs after the degradation of the particles by pectinolytic enzymes in the colon. ${ }^{(10,11)}$

However, the scientific literature lacks information on the relationship between the degradability of pectins from different plant sources and the concentration and activity of pectinases in the colon of humans.

The aim of this work was to study the swelling and degradation of CaPGPs in an artificial gastrointestinal medium at different concentrations of pectinase in the artificial medium of the colon.

\section{Materials and Methods}

\section{Objects of study and reagents}

In this work, we used LMEPs (10-12\%) from callus cultures of campion Silene vulgaris (M.) G. (SVC) and duckweed Lemna minor L. (LMC) with molecular masses of $>300 \mathrm{kDa}$, ${ }^{(7)}$ isolated and chemically characterized in the Department of Molecular Immunology and Biotechnology, LMEPs of apple AU-701 (AP, Herbstreith \& Fox KG, Germany) and citrus (CP, MP Biomedicals, Inc., Germany), pectinase from Aspergillus niger ( $\mathrm{P}$, Sigma, $1.18 \mathrm{U} / \mathrm{mg}$ of enzyme sample, USA), and calcium chloride $\left(\mathrm{CaCl}_{2}\right.$, Sigma, USA).

Formation of dry calcium-pectic gel particles and study of morphological properties

CaPGPs were obtained from pectins of callus cultures (SVC, LMC) and from commercial pectins (AP, CP) in the presence of calcium ions by the method of ionotropic gelling, which was described earlier. ${ }^{(10,}{ }^{11)}$ The pectins ( 30 or $50 \mathrm{mg}$ ) were dissolved in distilled water $(1 \mathrm{ml})$ by slow stirring with a magnetic stirrer MM-5 (Russia) by 2-5 hours at room temperature until complete dissolution.

Gel particles of spherical shape were prepared by dropby-drop injection of the pectin solution (3\% or 5\%) from a syringe through a needle with a hole diameter of $0.63 \mathrm{~mm}$ on the distance of $4-5 \mathrm{~cm}$ in the slowly stirred solution of calcium chloride $(0.34 \mathrm{M})$ and further stirring for 20 minutes at room temperature. The resulting gel particles were then washed three times in distilled water with stirring for 5 minutes and dried for $10-14 \mathrm{~h}$ at $37^{\circ} \mathrm{C}$.

Further, the diameter, surface area, volume and density of the calcium-pectic gel particles were determined using an optical microscope (Altami, Russia) with a camera and an image analysis program (ImageJ 1.46r program, National Institutes of Health, USA). For calibration, a linear scale was used, one pixel corresponded to $0.024 \mathrm{~mm}$.

\section{Study of swelling and degradation of calcium-pectic gel particles in simulated gastrointestinal media}

The swelling and degradation of CaPGPs were studied the under conditions simulating the gastrointestinal environment. (Fig.1) For these purposes, the simulated gastric fluid (SGF solution, $\mathrm{pH}$ 1.25), simulated intestinal fluid (SIF solution, $\mathrm{pH}$ 7.0) and simulated colonic fluid (SCF solution, $\mathrm{pH}$ 7.0). The SGF medium was prepared with $\mathrm{NaCl}(2.0 \mathrm{~g} / \mathrm{l})$, $\mathrm{KCl}(1.12 \mathrm{~g} / \mathrm{l}), \mathrm{KH}_{2} \mathrm{PO}_{4}(0.4 \mathrm{~g} / \mathrm{l})$ and $\mathrm{CaCl}_{2}(0.11 \mathrm{~g} / \mathrm{l})$.

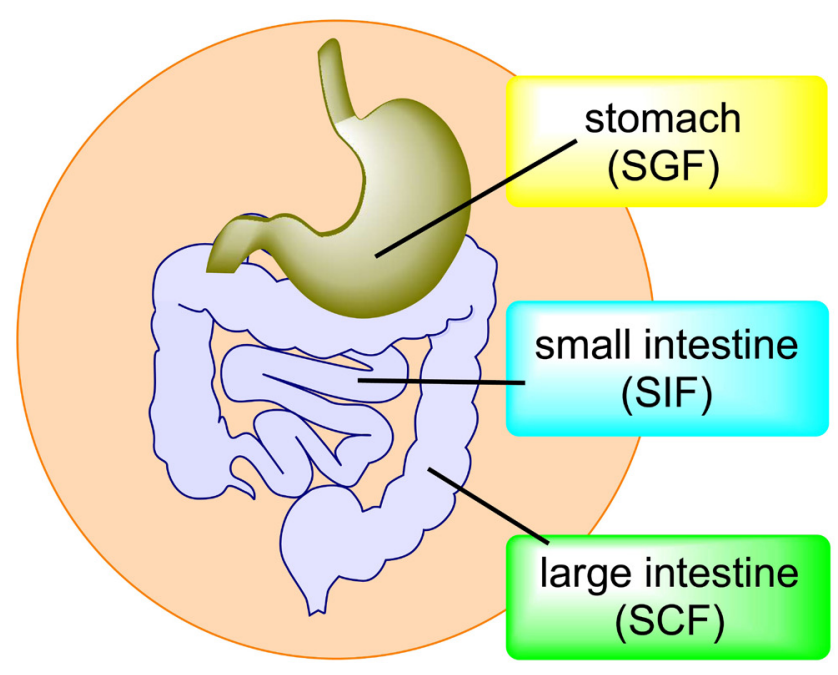

Fig. 1. Modeling of gastrointestinal tract parts of human by the artificial model environments.

The $\mathrm{pH}$ of the solution was adjusted to 1.25 by addition of $0.1 \mathrm{~N} \mathrm{HCl}$ solution. The SIF medium was prepared by addition of $1 \mathrm{~N} \mathrm{NaHCO}$ solution to the SGF solution to the $\mathrm{pH}$ value of 7.0. The SCF medium was prepared by addition of pectinase (Sigma, $1.18 \mathrm{U} / \mathrm{mg}$, USA) to the SIF solution (Sigma, USA). ${ }^{(12)}$ Three variants of the SCF medium with different concentrations of pectinase were used: $0.4 \mathrm{mg} / \mathrm{ml}$ $(0.5 \mathrm{U} / \mathrm{ml}), 0.8 \mathrm{mg} / \mathrm{ml}(1.0 \mathrm{U} / \mathrm{ml})$ and $1.7 \mathrm{mg} / \mathrm{ml}(2.0 \mathrm{U} / \mathrm{ml})$.

$10 \mathrm{mg}$ of gel particles of each pectin sample were placed in Petri dishes (diameter $3.5 \mathrm{~cm}$ ) and subsequently incubated in $3 \mathrm{ml}$ of the SGF (2 h), SIF (4 h) and SCF (18 h) solutions with shaking on a shaker (Titramax 1000, Heidolph, Germany) at $100 \mathrm{rpm}$ and $37^{\circ} \mathrm{C}$. The diameter, surface area, volume and density of 100 randomly selected gel particles of each 
pectin type were measured as described above after certain time intervals. The experiments were performed in triplicate. The degree of gel swelling (SD, \%) was determined by the formula ${ }^{(13)}: \mathrm{SD}=\left(\mathrm{D}_{1}-\mathrm{D}_{o}\right) / \mathrm{D}_{o} \times 100 \%$, where $\mathrm{D}_{1}$ - diameter of the particles $(\mathrm{mm})$ after a certain incubation time in the medium, $\mathrm{D}_{0}-$ initial diameter of the particles $(\mathrm{mm})$.

The statistical analysis was performed using the statistical software BioStat (version 4.03) and Microsoft Office Excel 2007. The mean (M) and standard deviation (SD) were calculated. Multiple comparisons were performed with one-way ANOVA and Tukey's HSD test. A probability value of $\mathrm{P}<0.05$ was considered statistically significant.

\section{Results and Discussion}

The gel-forming properties of pectins depend on the degree of methyl esterification of carboxyl groups of galacturonic acid residues, on the structure of pectin side chains, pectin concentration, $\mathrm{pH}$, calcium ion concentration, ionic strength of solution, and temperature. ${ }^{(14,15)}$ Spherical CaPGPs are formed as a result of the gelation, in which intermolecular cross-links arise between divalent calcium ions and negatively charged carboxyl groups of pectin macromolecules. ${ }^{(16,17)}$

The 3\% aqueous solutions of silenan, lemnan and apple pectins, and 5\% aqueous solutions of $\mathrm{CP}$ in the presence of calcium ions yield the spherical CaPGPs, which were subjected to determine their morphological characteristics (diameter, surface area, volume, density). The $3 \%$ aqueous solution of CP did not form spherical CaPGPs; it yielded only plate-like particles, which were excluded from further experiments.

The diameters of the dry CaPGPs obtained from the lemnan, silenan, apple and citrus pectins were $0.91 \pm 0.03 \mathrm{~mm}$, $1.07 \pm 0.07 \mathrm{~mm}, 1.21 \pm 0.05 \mathrm{~mm}$ and $1.73 \pm 0.20 \mathrm{~mm}$, respectively (Table 1).

Thus, the larger particles were formed from CP. However, the densest gel particles were formed from LP $(0.93 \pm 0.08 \mathrm{mg} /$ $\mathrm{mm}^{3}$ ); the density of the gel particles from silenan and apple pectins was lower $\left(0.64 \pm 0.08 \mathrm{mg} / \mathrm{mm}^{3}\right.$ and $0.51 \pm 0.05 \mathrm{mg} / \mathrm{mm}^{3}$, respectively). The gel particles formed by $\mathrm{CP}$ were characterized by the lowest density $\left(0.14 \pm 0.05 \mathrm{mg} / \mathrm{mm}^{3}\right)$. Morphological characteristics of CaPGPs obtained from pectins of callus cultures of silenan and lemnan and from commercial apple and citrus pectins have also been studied by other authors. ${ }^{(7,18)}$
In the study by E.Günter, ${ }^{(7)} \mathrm{CaPGPs}$ had dimensions and density comparable to our particles. The diameter of the dry gel particles was $1.13 \pm 0.08 \mathrm{~mm}$ (silenan), $1.14 \pm 0.08 \mathrm{~mm}$ (lemnan) and $1.35 \pm 0.08 \mathrm{~mm}$ (apple pectin), with the density of the gel particles of $0.62 \pm 0.13 \mathrm{mg} / \mathrm{mm}^{3}$ (silenan), $0.63 \pm 0.14 \mathrm{mg} / \mathrm{mm}^{3}$ (lemnan), $0.45 \pm 0.09 \mathrm{mg} / \mathrm{mm}^{3}$ (apple pectin).

Thus, stable spherical CaPGPs can be formed from pectin polysaccharides according to the described ionotropic gelling method. Based on the data from various authors, these particles have similar morphological characteristics (sizes and density). ${ }^{(7,16,18)}$

The influence of pectinase concentration (activity) in the simulated colonic fluid (SCF) on the degradability of CaPGPs was studied during their sequential incubation under the simulated GIT conditions: the simulated gastric fluid (SGF), the simulated intestinal fluid (SIF), and the simulated colonic fluid (SCF) with different concentrations of pectinase.

Three concentrations of pectinase (Sigma, USA) were used in the SCF medium: $0.4 \mathrm{mg} / \mathrm{ml}(0.5 \mathrm{U} / \mathrm{ml}), 0.8 \mathrm{mg} / \mathrm{ml}$ $(1.0 \mathrm{U} / \mathrm{ml})$ and $1.7 \mathrm{mg} / \mathrm{ml}(2.0 \mathrm{U} / \mathrm{ml})$. The concentration of pectinase of $1.7 \mathrm{mg} / \mathrm{ml}(2.0 \mathrm{U} / \mathrm{ml})$, also was used in the SCF medium by other researchers. ${ }^{(7,18)}$ The enzyme activity of $2.0 \mathrm{U} /$ $\mathrm{ml}$ at the concentration of pectinase of $1.7 \mathrm{mg} / \mathrm{ml}$ was obviously higher than the activity of pectinase, which we determined in the large intestine of mice (unpublished data), and higher than the activity of pectinase produced by fecal human bacteria. ${ }^{(19,20)}$ At pectinase concentrations of $0.8 \mathrm{mg} / \mathrm{ml}$ and $0.4 \mathrm{mg} / \mathrm{ml}$, the activity of the enzyme was lower than the previous one by 2 and 4 times, respectively. At the concentration of $0.4 \mathrm{mg} /$ $\mathrm{ml}$, the activity of the enzyme of $0.5 \mathrm{U} / \mathrm{ml}$ was comparable to the activity of the enzyme of $0.3 \mathrm{U} / \mathrm{ml}$ that we revealed in the colon of mice (unpublished data).

Nutrition components undergo complete degradation and are metabolized in different parts of GIT. We have established that CaPGPs formed from commercial pectins of apples and citrus fruits are completely degraded in the artificial medium of the small intestine (Fig.2).

The incubation of the gel particles from 3\% apple pectin AU-701 and 5\% CP in the simulated fluid of GIT led to their complete degradation in the simulated fluid of the small intestine SIF after 3 hours of incubation in it. Other authors have also showed that CaPGPs formed from apple or citrus pectins are degraded and dissolved in SIF medium..$^{(7,18)}$

Table 1.

Morphological characteristics of dry calcium-pectic gel particles

\begin{tabular}{|c|c|c|c|c|}
\hline $\begin{array}{c}\text { Gel } \\
\text { particles }\end{array}$ & $\begin{array}{l}\text { Diameter, } \\
\mathrm{mm}\end{array}$ & $\begin{array}{c}\text { Area } \\
\text { surface, } \mathrm{mm}^{2}\end{array}$ & $\begin{array}{c}\text { Volume } \\
\mathrm{mm}^{3}\end{array}$ & $\begin{array}{l}\text { Density, } \\
\mathrm{mg} / \mathrm{mm}^{3}\end{array}$ \\
\hline $\mathrm{Ca}-\mathrm{CP} \quad$ (1) & $1.73 \pm 0.20$ & $9.46 \pm 1.65$ & $2.82 \pm 0.88$ & $0.14 \pm 0.05$ \\
\hline Ca-AP (2) & $1.21 \pm 0.05$ & $4.34 \pm 0.28$ & $0.96 \pm 0.10$ & $0.51 \pm 0.05$ \\
\hline Ca-SVC (3) & $1.07 \pm 0.07$ & $3.67 \pm 0.47$ & $0.64 \pm 0.11$ & $0.64 \pm 0.12$ \\
\hline Ca-LMC (4) & $0.91 \pm 0.03$ & $2.67 \pm 0.17$ & $0.42 \pm 0.04$ & $0.93 \pm 0.08$ \\
\hline Statistics & $\begin{array}{l}\mathrm{F}=1044.5825 \mathrm{P}=0.0000 \\
\mathrm{P}_{1-2}=0.0000 \mathrm{P}_{1-3}=0.0000 \\
\mathrm{P}_{1-4}=0.0000 \mathrm{P}_{2-3}=0.0000 \\
\mathrm{P}_{2-4}=0.0000 \mathrm{P}_{3-4}=0.0000\end{array}$ & $\begin{array}{l}\mathrm{F}=1202.7884 \mathrm{P}=0.0000 \\
\mathrm{P}_{1-2}=0.0000 \mathrm{P}_{1-3}=0.0000 \\
\mathrm{P}^{1-2}=0.0000 \mathrm{P}^{2-3}=0.0000 \\
\mathrm{P}_{2-4}^{1-4}=0.0000 \mathrm{P}_{3-4}=0.0000\end{array}$ & $\begin{array}{l}\mathrm{F}=602.0298 \mathrm{P}=-0.0000 \\
\mathrm{P}_{1-2}=0.0000 \mathrm{P}_{1-3}=0.0000 \\
\mathrm{P}^{1-2}=0.0000 \mathrm{P}^{2-3}=0.0000 \\
\mathrm{P}_{2-4}=0.0000 \mathrm{P}_{3-4}=0.0030\end{array}$ & $\begin{array}{l}\mathrm{F}=1664.5995 \mathrm{P}=0.0000 \\
\mathrm{P}_{1-2}=0.0000 \mathrm{P}_{1-3}=0.0000 \\
\mathrm{P}_{1-4}=0.0000 \mathrm{P}_{2-3}=0.0000 \\
\mathrm{P}_{2-4}=0.0000 \mathrm{P}_{3-4}=0.0000\end{array}$ \\
\hline
\end{tabular}






Fig. 2. Swelling and degradation of CaPGPs of apple and citrus pectins under the conditions of simulated fluid of GIT.

Morphological changes and swelling and degradation of CaPGPs obtained from pectins of callus cultures of silenan and lemnan, were studied in the SCF medium containing different concentrations of pectinase. The silenan particles were degraded within 2 hours of incubation at the pectinase concentration of $1.7 \mathrm{mg} / \mathrm{ml}$, within $2-4$ hours of incubation at the concentration of $0.8 \mathrm{mg} / \mathrm{ml}$, and within $4-6$ hours of incubation in SCF at the concentration of $0.4 \mathrm{mg} / \mathrm{ml}$ (Fig.3).

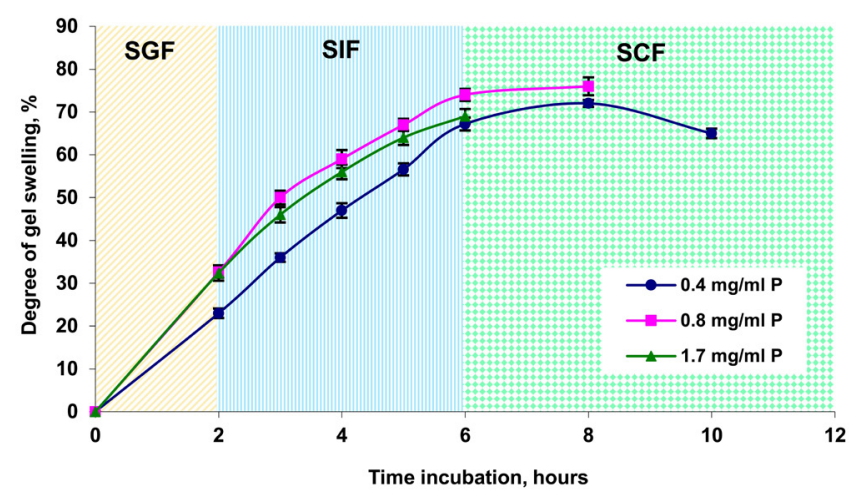

Fig. 3. Swelling and degradation of CaPGPs of silenan under the conditions of simulated fluid of GIT.

The lemnan gel particles are more resistant to degradation in the SCF medium than the particles from silenan, which was degraded during a longer incubation period in this medium (Fig.4).

The lemnan gel particles were degraded in the SCF medium at the pectinase concentrations of $1.7 \mathrm{mg} / \mathrm{ml}, 0.8 \mathrm{mg} / \mathrm{ml}$ or $0.4 \mathrm{mg} / \mathrm{ml}$ after 16,18 and 20 hours, respectively. Therefore, reducing pectinase concentration in the SCF medium by 2 or 4 times reduces the degradability of CaPGPs obtained from $\mathrm{SP}$, and the period of complete degradation and dissolution of the gel particles increases by 2 or 4 hours, respectively. It should be noted that in the absence of pectinase in the SCF medium, the gel particles obtained from silenan were resistant to degradation during the 18 hours of the incubation period. It is considered that the lower degradability of CaPGPs based on pectins of callus cultures in conditions of an artificial gastrointestinal environment, compared to gel particles from commercial pectins, can be explained by their higher gel density and lower degree of methoxylation. ${ }^{(14)}$

Earlier, we and other authors noted that the differences in stability of gel particles formed from different pectins may be due to differences in molecular sizes and in the fine structure of pectic macromolecules..$^{(4,5,16)}$

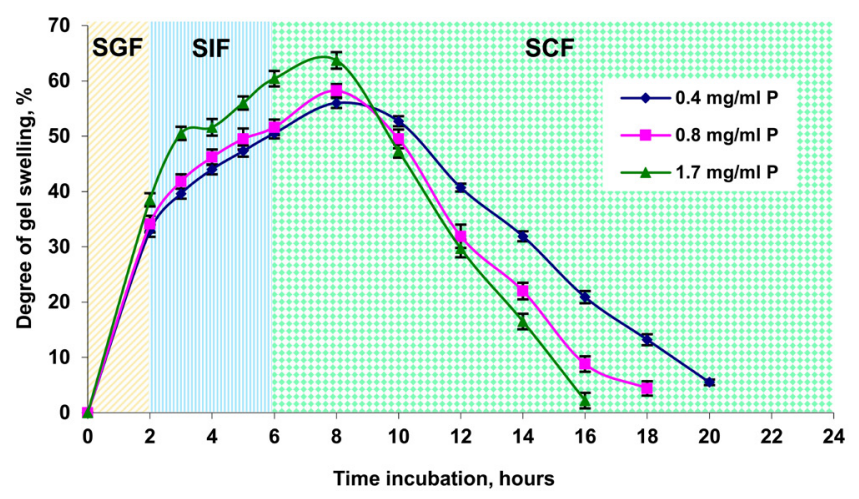

Fig. 4. Swelling and degradation of CaPGPs of lemnan under the conditions of simulated fluid of GIT.

Thus, the degradability of CaPGPs in the conditions of a gastrointestinal fluid depends on the plant source of pectin, on the density of gel particles and on the concentration of pectinase in the simulated fluid of the colon.

\section{Competing interests} interests.

The authors declare that they have no competing

\section{Sources of Funding}

The study was supported by the Federal Agency for Scientific Organisations (Project No. AAAA-A17-117012310147-8).

\section{Acknowledgments}

We thank Elena Günter, Oksana Popeyko and Anatoly Melekhin, who kindly provided samples of pectins from callus cultures for the study.

\section{References}

1. Kushak RI, Drapeau C, Winter HS. Pancreatic and intestinal enzyme activities in rats in response to balanced and unbalanced plant diets. Plant Foods Hum Nutr. 2002;57(34):245-55.

2. Macfarlane S, McBain AJ, Macfarlane GT. Consequences of biofilm and sessile growth in the large intestine. Adv Dent Res. 1997;11(1):59-68. 
3. Ovodov IuS. [Current information about pectin substances]. Bioorg Khim. 2009;35(3):293-310. [Article in Russian].

4. Patova OA, Golovchenko VV, Ovodov YuS. Pectic polysaccharides: structure and properties. Russ Chem Bull. 2014;63(9):1901-24.

5. Morris G, Kők S, Harding S, Adams G. Polysaccharide drug delivery systems based on pectin and chitosan. Biotechnol Genet Eng Rev. 2010;27:257-84.

6. Günter EA, Popeyko OV, Markov PA, Martinson EA, Litvinets SG, Durnev EA, et al. Swelling and morphology of calcium pectinate gel beads obtained from Silene vulgaris callus modified pectins. Carbohydr Polym. 2014;103:550-7. doi: 10.1016.j.carbpol.2013.12.071

7. Günter EA, Popeyko OV. Calcium pectinate gel beads obtained from callus cultures pectins as promising systems for colon-targeted drug delivery. Carbohydr Polym. 2016;147:490-9. doi: 10.1016/j.carbpol.2016.04.026

8. Dongowski G, LorenzA, Proll J. The degree of methylation influences the degradation of pectin in the intestinal tract of rats and in vitro. J Nutr. 2002;132(7):1935-44.

9. Dongowski G, Lorenz A, Anger H. Degradation of pectins with different degrees of esterification by Bacteroides thetaiotaomicron isolated from human gut flora. Appl Environ Microbiol. 2000;66(4):1321-7.

10. Sriamornsak P, Nunthanid J. Calcium pectinate gel beads for controlled release drug delivery: I. Preparation and in vitro release studies. Int J Pharm. 1998;160:207-12.

11. Sriamornsak P. Effect of calcium concentration, hardening agent and drying condition on release characteristics of oral proteins from calcium pectinate gel beads. Eur J Pharm Sci. 1999; 8(3):221-7.

12. Gebara C, Chaves KS, Ribeiro MCE, Souza FN, Grosso CRF, Gigante ML. Viability of Lactobacillus acidophilus
La5 in pectin-whey protein microparticles during exposure to simulated gastrointestinal conditions. Food Res Int. 2013; 51(2):872-8. doi: 10.1016/j.foodres.2013.02.008

13. Oliveira GF, Ferrari PC, Carvalho LQ, Evangelista RC. Chitosan-pectin multiparticulate systems associated with enteric polymers for colonic drug delivery. Carbohydr Polym. 2010;82(3):1004-09. doi: 10.1016/j.carbpol.2010.06.041

14. Günter EA, Popeyko OV, Istomina EI. Effect of carbohydrates on the composition and gel-forming properties of callus pectins Silene vulgaris. Chemistry of Natural Compounds. 2015;51:409-414.

15. Matveyev YuI. A method of calculating gelation parameters in aqueous solutions of biopolymers. Vysokomolekulyarnye Soedinenija. Seriya B. 2003;45(5):841-850.

16. Mikhailova EA, Melekhin AK, Belyy VA, Shubakov AA. Stability of hyaluronan-pectic gel particles in the conditions of the artificial gastrointestinal environment. International Journal of Biomedicine. 2017;7(4):310-314. doi: 10.21103/ Article7(4) OA8

17. Sriamornsak P., Kennedy R.A. Swelling and diffusion studies of calcium polysaccharide gels intended for film coating. Int J Pharm. 2008; 358(1-2):205-13. doi: 10.1016/j. ijpharm.2008.03.009.

18. Popov SV, Markov PA, Patova OA, Vityazev FV, Bakutova LA, Borisenkov MF, et al. In vitro gastrointestinalresistant pectin hydrogel particles for $\beta$-glucuronidase adsorption. J Biomater Sci Polym Ed. 2017;28(3):293-311. doi: 10.1080/09205063.2016.1268461

19. Englyst HN, Hay S, Macfarlane GT. Polysaccharide breakdown by mixed populations of human faecal bacteria. FEMS Microbiol Ecol. 1987;95:163-171.

20. Salyers AA. Energy sources of major intestinal fermentative anaerobes. Am J Clin Nutr. 1979;32(1):158-63. 